\title{
GGG JA EESTI KEELE SÜNTAKSI UURIMINE
}

\author{
MATI ERELT
}

\begin{abstract}
Annotatsioon. GGG keskseks uurimisvaldkonnaks oli eesti keele süntaks. Rühma esimestes töödes 1960. aastate keskel rakendati transformatoorse analüüsi meetodit, hiljem lähtuti generatiivsest grammatikast, sh eriti Charles Fillmore'i käändegrammatikast. Rühma olulisimaid töid oli Huno Rätsepa uurimus eesti keele verbikesksete lausemallide kohta (1978). Pärast GGG tegevuse vaibumist kujunes 1970ndate keskel grammatikauurimise keskuseks Keele ja Kirjanduse Instituudi grammatikarühm, mille tuumiku moodustasid endised GGG liikmed. Rühm andis välja uurimuste sarja „Ars Grammatica“ ning koostas eesti keele teadusliku grammatika. 1990. aastate keskel hakkas eesti süntaksiuurimises domineerima funktsionaal-tüpoloogiline suund ning uurimise kese nihkus taas Tartu Ülikooli, kus endiste GGG liikmete juhendusel kasvas peale uus põlvkond süntaksiuurijaid. Probleemiuurimise kõrval koostatakse Tartu Ülikoolis praegu uut terviksüntaksit, mis peab valmima 2016. aastal.
\end{abstract}

Võtmesõnad: eesti keele uurimise ajalugu, süntaks

Nagu generatiivses grammatikas (GG) üldse nii ka Tartu ülikooli GGG liikmete tegevuses on üheks keskseks valdkonnaks olnud süntaks. Järgnev on lühikokkuvõte sellest, mida GGG liikmed on eesti keele süntaksi uurimisel teinud, seda nii GGG toimimisajal kui ka pärast seda.

1. GGG tegutsemise algusajal 1960. aastate keskel oli generatiivne grammatika kahtlemata maailma lingvistikas kõige populaarsemaid suundi. GG teooriale oli aluse pannud Noam Chomsky oma raamatuga „Syntactic Structures“ (1957) ning parajasti meie rühma tegutsemisajal ilmus talt GG teooriat edasi arendav töö „Aspects of the Theory of Syntax“ (1965), kus ta muutis oma esialgse grammatikamudeli oluliselt semantilisemaks. Loomulikult pakkus see kõik suurt huvi ka meie rühma liikmetele, kusjuures kujunes peaaegu tavaks kirjutiste algul öelda, et see on eeltöö eesti keele generatiivse grammatika koostamiseks. Tegelikult 
küll oli üks eesti keele generatiivne grammatika juba koostatud, nimelt ameeriklase Robert Harmsi „Estonian Grammar“ (1962), aga selles oli süntaksit ainult 28 lehekülge. Muidugi tahtsime meie koostada midagi hoopis põhjalikumat. Nagu teada, jäi see soov täitumata. Koostati küll üksikuid generatiivseid grammatikafragmente, aga valdavalt olid rühma süntaksiuurimused siiski analüüsivad. See on ka loomulik, sest on ju analüüs sünteesi normaalne eeletapp.

2. GGG esimestes töödes lähtuti Ameerika deskriptiivse lingvistika analüüsimeetodeist. Ameerika deskriptiivne lingvistika oli puhtformaalne strukturalistlik suund, mis kindlate analüüsiprotseduuride abil leidis tekstist kirjeldatava keele grammatika. Need protseduurid olid distributiivne analüüs, vahetute moodustajate analüüs ja transformatoorne analüüs. Meie rühma liikmed kasutasid ennekõike transformatoorset analüüsi. Kuigi see Zellig Harrise (1957) loodud analüüsimeetod oli mõeldud keele formaalse struktuuri avastamiseks, leidis see kasutust ka polüseemsete vormide tähenduste eristamisel. Eeldati, et sama vormi erisugused transformatsioonivõimalused näitavad vormi eri tähenduste olemasolu. Meid huvitaski just see aspekt. Üliõpilane Haldur Õim kasutas transformatoorse analüüsi meetodit verbide tulema, saama, pidama, minema, jääma, hakkama jt leksikaalsete tähenduste eristamiseks, üliõpilane Mati Erelt analüüsis selle abil eesti keele käänete funktsioone (vrd nt elatiivse nimisõna transformatsioonivõimalusi: Ta tunneb narri naerust $\rightarrow$ naeru järgi; Ta maksab piletist $\rightarrow$ pileti eest 20 eurot). Sama meetodit kasutas ka Ellen Uuspõld oma väitekirjas (1966), mis käsitles lauselühendite (hilisema terminiga sekundaartarindid) struktuuri ja tähendust. Uuspõllu töö oli esimene põhjalik uurimus eesti lauselühendite kohta ning ühtlasi esimene süntaksialane kandidaadiväitekiri GGG liikmetelt.

3. Deskriptiivsest lingvistikast lähtunud, kuid kirjeldussuuna analüüsist sünteesiks pööranud generatiivne grammatika oli esialgu puhtformaalne keelemudel ja andis väljundiks nn grammatiliselt õiged laused, sealhulgas sellised nagu Värvusetud rohelised ideed magasid raevukalt. Kuid alates 1960. aastate keskpaigast hakkas see järk-järgult muutuma semantilisemaks. Chomsky „Aspects of the Theory of Syntax“ kaotas süntaksist tähendust muutvad transformatsioonid ja tegi süntaksi baaskomponendi selle võrra abstraktsemaks, nn süvastruktuure genereerivaks komponendiks. Baaskomponendile lisas abstraktsust seegi, et sinna lisati ka süntaktilisi funktsioone väljendavad mõisted 'predikaat', 'subjekt' ja 
'objekt'. Peale selle toodi grammatikasse semantikakomponent, mille ülesandeks oli anda pindstruktuuridele semantiline tõlgendus. Järgmine samm baaskomponendi abstraktsemaks muutmisel oli Charles Fillmore' $i$ käändegrammatika (ingl case grammar), mille ta esitas esimest korda töös „The Case for Case“ (1968). Fillmore tõi grammatikasse käände- ehk semantilise rolli mõiste (agent, patsient, instrument jne) ja kirjeldas lause süvastruktuuri predikaadi ja käändefunktsioone täitvate argumentide termineis. Subjekt ja objekt süvastruktuuri mõistete hulka enam ei kuulunud, need grammatilised liikmed loodi transformatsioonidega, nt subjekt nn topikalisatsiooniga.

GGG-s tutvuti Fillmore'i tööga peaaegu kohe pärast selle ilmumist ja üritati seda rakendada ka eesti lauseehituse kirjeldamisel. Mati Erelt kasutas Fillmore'i tüüpi generatiivgrammatikat komparatsiooni kirjeldamisel (Erelt 1970, 1971), Reet Kasik nominalisatsiooni kirjeldustes (1970). Generatiivne oli ka Jaan Kaplinski liitsõnakirjeldus (1968). Haldur Õim aga lähtus generatiivsest semantikast oma kandidaadiväitekirjas (1971), mis käsitles isiku mõistega seotud sõnarühmade tähendust.

Suurima panuse eesti keele süntaksi uurimisse moodsas vaimus andis Huno Rätsep. 1960. aastatel oli ta hakanud uurima verbi rektsioonistruktuure ja pidas tähendusest lähtumist rektsiooniliste lausemallide kirjeldamisel väga vajalikuks, kuid ei rahuldunud Fillmore'i pakutud käänderollidega, vaid esitas mitmes artiklis (nt Rätsep 1970, 1972) hoopis detailsema, (tegelikku keelekasutust arvestava) süvasituatsioonide käsitluse. Oma doktoriväitekirjas (1974) ja selle põhjal koostatud monograafias „Eesti keele lihtlausete tüübid“ (Rätsep 1978) esitas ta küll ainult formaalsed lausemallid, lihtlausete pindstruktuurid, jättes süvasituatsioonide kirjelduse tuleviku ülesandeks. Töö suurt mahtu arvestades on see ka täiesti mõistetav. Kokku oli Rätsepa töös 1277 lausemalli, mis olid taandatud 380 elementaarlausele, s.o ainult obligatoorseid laiendeid sisaldavatele mallidele.

4. 1970. aastate keskel hakkas süntaksiuurimise kese Tallinna poole nihkuma. 1976. aastal loodi Keele ja Kirjanduse Instituudis (KKI) grammatikarühm, kus hakkas tööle mitu GGG liiget, süntaksiuurijatest Mati Erelt ja Helle Metslang (Niinemägi). Rühma juhatas esialgu Henno Rajandi, eesti (morfo)süntaksi ja ühtlasi generatiivgrammatika parimaid tundjaid, hiljem Mati Erelt. Grammatikarühmaga liitusid ka nooremad süntaksiuurijad Peep Nemvalts, Kaja Tael ja Joel Sang. 
Grammatikarühm moodustati selleks, et koostada eesti keele teaduslik grammatika. Koostama hakati 1983. aastal, enne seda oli ettevalmistusperiood, mil täideti uurimislünki. Kujunesid välja mitmedki põhimõtted, millest lähtuti nii edasistes uurimustes kui ka grammatika koostamisel. Lauset ei kirjeldatud üksnes formaalsete tunnuste alusel eristatud lauseliikmete termineis, vaid arvestati ka lause süntaktiliselt relevantset tähendusstruktuuri juba nimetatud semantiliste rollide (agent, patsient, instrument jne) termineis, samuti pragmaatilist (teema-reema) struktuuri. Esitati lause põhitüübid (normaallause, olemasolulause ja kogeja-omajalause) selle põhjal, kuidas kolm struktuurikihti (semantiline, pragmaatiline ja grammatiline (lauseliikmeline)) omavahel klapivad. Liigitustes, nii sõnaliikide kui ka igasuguste muude klassifikatsioonide puhul, lähtuti Tšehhi funktsionaalsest lingvistikast pärinevast tsentri-perifeeria põhimõttest ja psühholoogide (Eleanor Rosch jt) prototüübiteooriast.

Nii enne grammatika koostamist kui ka paralleelselt sellega kaitsti väitekirju ning anti välja grammatikauurimuste sarja „Ars Grammatica“, mida ilmus üle 30 vihiku. Endistest GGG liikmetest kaitses Helle Metslang 1978. aastal kandidaadiväitekirja eesti regilaulu parallelismist, mida ta kirjeldas muu hulgas infostruktuurilisest aspektist, ning Mati Erelt 1981. aastal doktoriväitekirja eesti keele adjektiivide süntaksist, millest konkreetne adjektiivide osa ilmus raamatuna „Eesti adjektiivisüntaks“ (1986). Teistest grammatikarühma liikmetest või grammatikarühmaga seotud süntaksiuurijatest kaitses Kaja Tael 1989 väitekirja eesti keele sõnajärjest ning Joel Sang 1980 eitusest eesti keeles (ilmus raamatuna 1983).

Mitmed olulised süntaksiosad, nagu aspekt (eriti objektiga seonduv), tegumood, juba nimetatud eitus, adjektiivide süntaks, sõnajärg jne töötati oma aja kohta küllaltki hästi läbi. Mõistagi tugines grammatika oma põhiosas siiski ka paljude teiste süntaktikute uurimustele, nii moodsatele (nt Huno Rätsepa, Ellen Uuspõllu uurimused) kui ka traditsioonilistele (nt Karl Kondi, Lehte Rannuti, Karl Mihkla, Nikolai Remmeli, Elli Riikoja, Valter Tauli jt tööd).

Grammatika süntaksiosa valmis 1980. aastate lõpus ning ilmus trükist 1993 (EKG II). Selle põhiautoriteks olid Mati Erelt ja Helle Metslang, vähemal määral Kaja Tael ja Henno Rajandi.

5. Pärast grammatika valmimist ja KKI grammatikarühma lagunemist 1990. aastate algul hakkas eesti süntaksiuurimises tasapisi domineerima uus, funktsionaal-tüpoloogiline suund. See oli kooskõlas maailma 
lingvistika üldiste suundumustega ning ka eesti lingvistikas ei tekkinud see tühjale kohale. Eesti uurijatest tuleb taas nimetada Huno Rätsepat, kes oli 1981 avaldanud kirjutise „Eesti keele lihtlausete põhitüübid kontensiivse tüpoloogia vaatekohast", hiljem veel paar artiklit.

Mõistagi ei ole meie uurijad tegelnud mitte keeletüpoloogiaga selle laias tähenduses, s.o tüpoloogilise klassifitseerimisega ja tüpoloogiliste seaduspärasuste avastamisega, vaid eesti keele nähtuste seletamisega juba avastatud (või vähemasti oletuslike) tüpoloogiliste seaduspärasuste abil. Teiste sõnadega, eesti keele kirjeldamisel rakendatakse tüpoloogilist meetodit ja püütakse fikseerida eesti keele kohta ühe või teise nähtuse tüpoloogilisel kaardil, sageli kõrvutavalt soome keele vm läänemeresoome keelega, ka eesti murdeid või eri ajaperioode võrreldes. Üks esimesi töid selles suunas oli Helle Metslangi doktoriväitekiri „Temporal Relations in the Predicate and the Grammatical System of Estonian and Finnish“ (1994), milles ta võrdles tüpoloogilisest aspektist eesti ja soome keelt. Hiljem on selliseid töid, põhiliselt artiklite ja artikliväitekirjadena, ilmunud kümneid ja kümneid. Seda laadi süntaktilise uurimistöö keskuseks on saanud Tartu Ülikool, kuid sellega on tegeldud ka Tallinna Ülikoolis ja Eesti Keele Instituudis. Tartu Ülikooli eesti keele õppetool (praegune osakond) andis aastatel 1996-2001 välja ka kogumikku „Estonian: Typological Studies“ (Erelt (ed.)). Seda ilmus küll vaid viis, sest kuivõrd teadustulemuste hindamine muutus järjest formaalsemaks (ainult publikatsiooni ilmumiskohta, mitte selle sisu arvestavaks), siis polnud mõtet sarja enam jätkata.

Nii tüpoloogilistes kirjeldustes kui ka väljaspool neid on rakendatud grammatiseerumisteooriat ning eesti keele süntaktilistes kirjeldustes on koha leidnud kognitiivne grammatikateooria, sealhulgas konstruktsioonigrammatika. Peale on kasvanud uus ja rahvusvaheliselt suhtlev põlvkond süntaksiuurijaid, mistõttu praegu on eesti süntaks (täpsemalt morfosüntaks) suhteliselt hästi uurijatega kaetud.

6. Rööpselt kirjeldatud uurimistööga on praegu Tartu Ülikoolis käimas uus uurimisprojekt - uue eesti keele süntaksi koostamine. See on osa suuremast eesti keele tervikkäsitluste projektist. Süntaksi tervikkäsitlusest on seni ilmunud kaks raamatut (Erelt 2013 ja 2014), kogu töö ilmub 2016. aasta jooksul. Peale siinse kirjutise autori on selle koostamisel suuremal või vähemal määral osalenud ka teisi Tartu süntaksiuurijaid: Helle Metslang, Renate Pajusalu, Tiit Hennoste, Liina Lindström, Ann Veismann 
ja Helen Plado. Uus süntaks arvestab neid muutusi, mis eesti keele süntaksikirjelduses EKG-le järgnenud ajal on toimunud, kirjeldus lähtub tekstikorpustest ning haarab mõnevõrra ka suulise keele nähtusi, ehkki suulise keele täielik kirjeldus koostatakse küll Tiit Hennoste juhtimisel eraldi tervikkäsitlusena. Kõigi tervikkäsitluste valmimise järel tehakse nende põhjal ka uus grammatika, mis peab valmima 2018.

Kokkuvõtteks võib öelda, et eesti keele süntaksiuurimine, mille moderniseerumine sai alguse pool sajandit tagasi suures osas GGG tegevuse tulemusena, on sama liini jätkates jõudnud seisu, mis pole sugugi halb.

\section{Kirjandus}

Chomsky, Noam 1957. Syntactic Structures. The Hague.

Chomsky, Noam 1965. Aspects of the Theory of Syntax. Cambridge, Mass.

EKG II = Mati Erelt, Reet Kasik, Helle Metslang, Henno Rajandi, Kristiina Ross, Henn Saari, Kaja Tael, Silvi Vare 1993. Eesti keele grammatika. II. Süntaks. Lisa: Kiri. Peatoim. Mati Erelt, toim. Tiiu Erelt, Henn Saari, Ülle Viks. Tallinn: Eesti Teaduste Akadeemia Keele ja Kirjanduse Instituut.

Erelt, Mati 1970, 1971. Adjektiivide gradatsioon ja komparatsioon eesti keeles. - Keel ja struktuur 4, 3-80; 5, 3-34.

Erelt, Mati 1986. Eesti adjektiivisüntaks. (= Eesti NSV Teaduste Akadeemia Emakeele Seltsi toimetised 19.) Tallinn: Valgus.

Erelt, Mati (ed.). Estonian: Typological Studies I-V. (= Publications of the Department of Estonian of the University of Tartu 4, 8, 11, 14, 18.) Tartu, 1996, 1997, 1999, 2000, 2001.

Erelt, Mati 2013. Eesti keele lauseõpetus. Sissejuhatus. Öeldis. (= Tartu Ülikooli eesti keele osakonna preprindid 4.) Tartu.

Erelt, Mati 2014. Eesti keele lauseõpetus. Komplekslause. Tartu Ülikooli eesti keele osakond. Tartu.

Fillmore, Charles 1968. The case for case. - Universals in Linguistic Theory. Eds. Emmon Bach, Robert T. Harms. London: Holt, Rinehart and Winston, $1-88$.

Harms, Robert T. 1962. Estonian Grammar. (= Indiana University Publications. Uralic and Altaic Series 12.) Bloomington: Indiana University.

Harris, Zellig S. 1957. Co-occurrence and transformation in linguistic structure. Language 33 (3), 283-340. http://dx.doi.org/10.2307/411155.

Kaplinski, Jaan 1968. Liitsõna moodustamise tüübid eesti keeles (generatiivse grammatika seisukohalt). - Keele modelleerimise probleeme 2. (= Tartu Riikliku Ülikooli toimetised 218.) Tartu, 297-374.

Kasik, Reet 1970. Lähtelause subjekt ja objekt deverbaalsubstantiivilistes nominalisatsioonides. - Keel ja struktuur 4. Tartu, 121-135. 
Metslang, Helle 1994. Temporal Relations in the Predicate and the Grammatical System of Estonian and Finnish. (= Oulun Yliopiston suomen ja saamen kielen laitoksen tutkimusraportteja 39.) Oulu.

Rätsep, Huno 1970. Government structure types of the verb and situation analysis. - Annual Meeting of Research Group for Generative Grammar, 1970. Abstracts. Tartu State University. Tartu, 28-34.

Rätsep, Huno 1972. Süvasituatsioonidest ja lausemallidest. - Emakeele Seltsi aastaraamat 18 (1972). Eesti NSV Teaduste Akadeemia Emakeele Selts. Tallinn: Eesti Raamat, 55-70.

Rätsep, Huno 1978. Eesti keele lihtlausete tüübid. (= Eesti NSV Teaduste Akadeemia Emakeele Seltsi toimetised 12.) Tallinn: Valgus.

Rätsep, Huno 1981. Eesti keele lihtlausete põhitüübid kontensiivse tüpoloogia vaatekohast. - Eesti keele grammatika probleeme. (= Tartu Riikliku Ülikooli toimetised 574, Töid eesti filoloogia alalt VIII.) Tartu: Tartu Riiklik Ülikool, 35-50.

Sang, Joel 1983. Eitus eesti keeles. Eesti NSV Teaduste Akadeemia Keele ja Kirjanduse Instituut. Tallinn: Valgus.

Uuspõld, Ellen 1966. Määrusliku des-, mata-, nud- ( nuna-) ja tud- ( tuna-) konstruktsiooni struktuur ja tähendus. - Keele modelleerimise probleeme 1. (= Tartu Riikliku Ülikooli toimetised 188.) Tartu, 4-196.

Õim, Haldur 1971. Isiku mõistega seotud sõnarühmade semantiline struktuur eesti keeles. - Keele modelleerimise probleeme 4. (= Tartu Riikliku Ülikooli toimetised 278.) Tartu: 3-260. 


\title{
GGG and the study of Estonian syntax
}

\author{
MATI ERELT
}

The central field of study of the Research Group for Generative Grammar (GGG) was Estonian syntax. In the group's first works, in the mid-1960s, the method of transformation analysis was used; later, the preferred framework was generative grammar, especially Charles Fillmore's case grammar. Among the group's most important works was Huno Rätsep's study of verb-governed sentence patterns (1978). After the abatement of the GGG's activity, the main center of grammar studies became the grammar group of the Institute of Language and Literature, the core of which consisted of former GGG members. The group published the series of studies "Ars Grammatica" and compiled an descriptive grammar of Estonian. In the mid-1990s, Estonian syntax studies came to be dominated by the functional-typological approach and the center for research shifted back to the University of Tartu, where a new generation of syntax researchers developed under the guidance of former GGG members. In addition to studying various problems of syntax, a new comprehensive account of Estonian syntax is being compiled at the University of Tartu, due to be completed in 2016.

Keywords: research history of Estonian, syntax

\author{
Mati Erelt \\ eesti ja üldkeeleteaduse instituut \\ Tartu Ülikool \\ Jakobi 2 \\ 51014 Tartu Ülikool \\ mati.erelt@ut.ee
}

